\title{
Internet banking
}

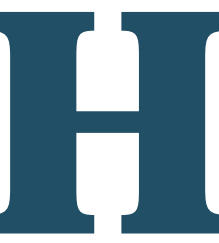

oje em dia, a utilização de Internet banking já está incorporada às práticas do negócio bancário. Contudo, há não mais do que dez anos, a realidade era bem diferente. Utilizando o estudo de caso de um banco brasileiro pioneiro na adoção da Internet, o artigo explora fatores para a incorporação e consolidação desta na estratégia do setor bancário. A análise do caso mostra que a adoção denovastecnologiaséfenômeno complexo queenvolvedimensões de ordem social, cultural, política e, naturalmente, econômica.

por Eduardo H. Diniz e Heloísa Mônaco dos Santos FGVEAESP

O Internet banking, isto é, a utilização da Internet para oferta de serviços bancários, é a principal inovação tecnológica incorporada aos serviços bancários na última década. Associado à demanda dos clientes por maior conveniência e interesse dos bancos por economia, precisão e automação, o Internet banking, que no início era consi- derado apenas mais um canal para a distribuição de serviços bancários, passou a estar no centro das discussões sobre a evolução e o futuro dos bancos.

Mais do que um canal com os clientes, a Internet já faz parte hoje de processos internos, ao ser incorporada nas Intranets e portais corporativos, etambém é ferramenta 
essencial para a estruturação de metodologias de CRM e BI nos bancos, por permitir uma coleta de dados de clientes muito mais rica.

Contudo, um observador talvez tenha dificuldade em imaginar que há dez anos poucos acreditavam que a Internet poderia ser uma tecnologia com poder tão transformador no setor bancário. Além de ser considerado um ambiente muito inseguro e cheio de hackers, parecia mais idéia de acadêmicos, com pouca aplicação no mundo corporativo. A pergunta que então podemos fazer é: como os visionários de dez anos atrás conseguiram persuadir seus pares sobre as vantagens do uso da Internet para os bancos?

Premissas. As tecnologias não evoluem somente sob o ímpeto de uma lógica interna, tecnológica ou econômica. Evoluem porque são pressionadas por fatores históricos, econômicos, políticos, psicológicos e sociológicos de uma determinada organização. dimento dos movimentos de diversos atores que atuaram, e atuam, para moldá-la em sua forma atual.

Embora a traj etória de incorporação da Internet pelo Banco seja um fluxo contínuo envolvendo diversos atores ao longo do tempo, podem ser identificados três momentos distintos desse processo: a etapa inicial, de associação entre o Banco e a Internet; a etapa de consolidação e expansão do uso da Internet no ambiente do Banco; e a etapa de transformação, quando a Internet se torna não apenas essencial e indissolúvel nos processos bancários, mas também se torna a alavanca de criação de novas oportunidades de negócio.

O começo. Em 1994, a Embratel disponibilizou ao Banco uma senha para acesso à Internet, novidade na época para os brasileiros fora do ambiente acadêmico e governamental. N esse mesmo ano, o Banco enviou um de seus funcionários para uma importante feira do setor de informática no exterior, que trouxe para a instituição o recém-lançado programa de consulta, ou navegador para Internet, chamado "Internet in a box". Esse produto abria as portas da Internet para alguns poucos funcionários que pesquisavam inovações tecnológicas e já estavam interessados na Web.

Após al gumas experimentações, a equipe responsável pelo projeto de implantação decidiu que seria útil criar uma página do Banco na Internet. Porém, antes disso, precisava obter autorização da Diretoria para o projeto e também explicar às várias pessoas dentro da organização o que era
Para entendermos melhor como ocorreu a incorporação da Internet no setor bancário, utilizaremos um exemplo concreto. Pesquisamos como um dos maiores bancos brasileiros, aqui denominado apenas como Banco, pioneiro na adoção de diversas tecnologias da informação no país, conseguiu incorporar essa tecnologia à sua cultura e seu modo de funcionamento. Adicionalmente, a investigação da trajetória da Internet em um banco pioneiro na adoção dessa tecnologia contribui também para o enten- a Internet, visto que poucos a conheciam. Para apresentar as vantagens de se criar um site para o Banco, os pesquisadores acessavam sites disponíveis na Internet naquela época, destacando para os diretores que aquela tecnologia permitiria atender à necessidade do Banco de divulgação institucional, tanto no Brasil quanto no exterior.

Além da divulgação de informações sobre o Banco, a equipe identificou que a Internet atenderia também a necessidade de o Banco de "ser transparente ao cliente", isto 
é, informá-lo sobre todos os passos relacionados às suas movimentações financeiras realizadas na instituição. Esse ponto foi considerado particularmente importante para a empresa, que, desde a sua origem, mantinha registros realizados manual mente das movimentações em seus livros e, com a tecnologia disponível na época, disponibilizava uma cópia aos clientes.

Uma vez aprovado o projeto, a equipe iniciou o processo de desenvolvimento de um site institucional, utilizando como fonte do conteúdo a ser disponibilizado um documento que já existia, com textos em português e inglês. Esse ponto de partida facilitou a construção do site e fez com que a equipe se concentrasse melhor em seus aspectos técnicos. $\mathrm{N}$ essa empreitada, contaram com 0 apoio da Embratel, visto que poucos, naquela época, sabiam como desenvolver um site.

Em 1995 foi lançado o primeiro site do Banco, um dos primeiros do Brasil na Internet, que trazia a história da instituição, relatórios de administração, demonstrações financeiras, notícias, informações sobre produtos,

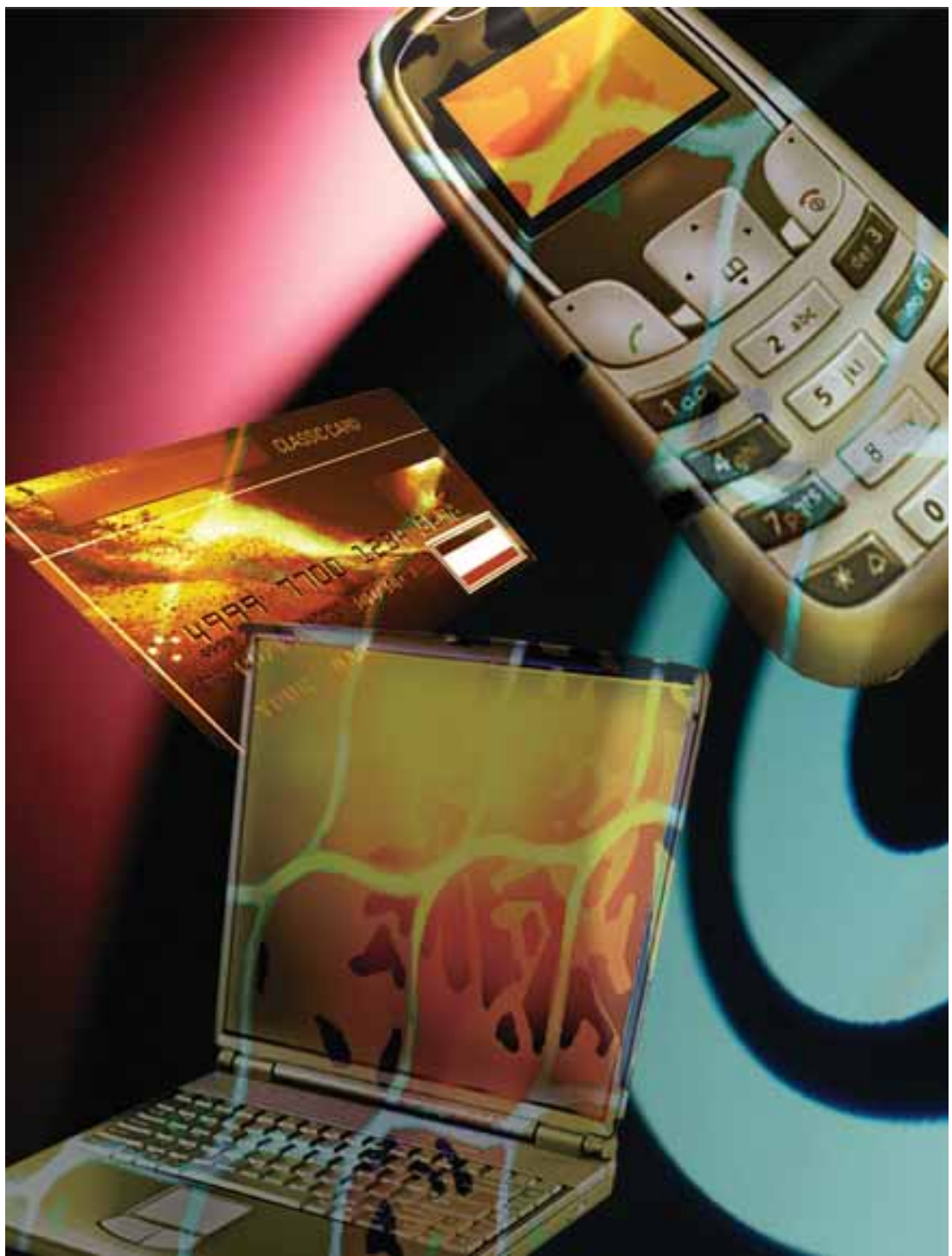
serviços e tecnologia. Além disso, tratava das ações sociais por ele desenvolvidas. Os poucos clientes que já fossem internautas também podiam solicitar cartões de crédito on-line.

A partir do momento em que a página foi disponibilizada, o Banco começou a receber e-mails, na maioria de brasileiros no exterior, que elogiavam a iniciativa. Após essa fase de elogios, as mensagens recebidas passaram a questionar quando seria possível consultar o saldo e extratos das contas correntes por meio da Internet. Em um determinado momento, $80 \%$ desses e-mails começaram a questionar a utilidade do site, praticamente "exigind o" que fossem disponibilizados outros serviços. 0 Banco não re-

sistiu à pressão dos clientes e decidiu iniciar o desenvolvimento da solução que daria ao site institucional a possibilidade de nele se realizarem transações bancárias.

No início, o Internet banking contava com as funcionalidades de consulta a saldos e extratos, solicitação de alteração de endereço, cópias de documentos e tal ões de cheques, agendamento de boletos de cobrança, investimentos, transferência de fundos entre contas do próprio Banco e pagamento de contas, serviço no qual foi pioneiro no mundo a disponibilizar pela Internet.

Q uatro fatos relacionados ao lançamento, em 1996, do Internet banking desse Banco se destacam: a experiên- 
cia adquirida com a implantação das soluções de home banking e office banking; 0 desenvolvimento do pagamento seguro por meio eletrônico; o desenvolvimento da solução do boleto bancário; e o desenvolvimento, na época, de uma nova solução de office banking.

A consoli dação. A fase de consolidação e expansão da associação entre as tecnologias da Internet e os negócios do Banco foi marcada por novo ciclo de interações para identificar 0 interesse pela tecnologia e para consolidar alianças em torno da solução envolvendo a Internet, tanto de atores internos quanto externos ao Banco. Observouse nessa fase intensa mobilização de recursos para consolidar a associação, assim como o aumento da quantidade de atores envolvidos.
Contudo, nessa fase a Internet ainda era vista meramente como um canal bancário, com a diferença de ser mais versátil e barato do que os outros. A quantidade de serviços ofertados pelo Internet banking crescia enquanto o número de usuários do canal avançava. Inesperadamente, entretanto, o Banco teve de lidar com uma nova questão: o perfil dos clientes usuários do Internet banking era substancialmente diferente dos clientes tradicionais do Banco. Ao perceber o potencial da Internet para atrair clientes da classe A e B, a instituição começou a desenvolver estratégias específicas para esse segmento mais rentável, como um site de investimentos, por exemplo.

O sucesso dessa nova abordagem elevou a importância da Internet no Banco. A té o momento vista como um canal com custo de transação mais baixo, ela começou a atrair a atenção pela oportunidade de extrair informações mais detalhadas dos clientes. 0 Internet banking começou então a ser considerado um canal potencialmente interessante para desenvolver relacionamento com clientes.

Além disso, outras oportunidades apareceram inesperadamente. Por considerar que o comércio eletrônico já estava em franca evolução, o Banco acreditou que poderia incentivar o uso de meios de pagamento eletrônico adaptados ao mundo da Internet. Observando que a Micro-
A partir do lançamento do Internet banking (1996), teve início uma série de ações voltadas a divul gar e apresentar a solução, tanto internamente - principalmente para os funcionários das agências - como externamente, para que todos os clientes passassem a conhecer, e utilizar, essa nova forma de contato com o Banco. Internamente, a instituição elaborou programas de treinamento e incentivos para que os funcionários utilizassem as aplicações disponíveis na Internet. Externamente iniciou uma série de campanhas publicitárias divulgando o novo canal de comunicação com o Banco. 0 esforço justificavase porque a utilização da Internet também permitiria uma redução geral de custos. soft e a Visa já estavam trabal hando no desenvolvimento de uma carteira eletrônica, o Banco também desenvolveu a sua. Ao apresentar o novo produto para o setor responsável pela propaganda, foi preciso explicar que aquilo serviria para se utilizar em lojas na Internet. Então o Banco descobriu que precisava criar também as lojas. A carteira não fez muito sucesso, mas o shopping eletrônico criado ajudou a atrair novos clientes corporativos, interessados em utilizar sua infra-estrutura de comércio el etrônico.

A incorporação. Atualmente a Internet parece permear a infra-estrutura da organização de uma forma significativa. Progressivamente ela passará a ser a infra- 
estrutura dos terminais de auto-atendimento, ampliando a flexibilidade de mudanças, de venda cruzada e de conhecimento sobre o cliente.

Por sua vez, as Intranets do Banco evoluíram em direção a um processo muito estruturado: utilizando-se as tecnologias da Internet, hoje a idéia de portal corporativo está na ordem do dia. A idéia de se desenvolver um ambiente para os funcionários queintegre plataformas, funcione como canal interno de comunicação e também de colaboração transformou-se em um modelo a ser perseguido.

A Internet também incentivou o Banco a desenvolver melhor os canais voltados para segmentos específicos de clientes. A análise sistemática de dados de clientes usuários da Internet ajudou a direcionar a criação de portais exclusivos para clientes de diferentes perfis e também provocou o direcionamento de investimentos significativos para a criação de um novo projeto de cadastro de clientes.

A instituição desenvolveu e desenvolve uma série de estratégias para ampliar a utilização do Internet banking por meio de microcomputadores. Porém o Banco considera que a evolução da Internet está vinculada a outros dispositivos, como, por exemplo, o celular, que poder ter associado a si a tecnologia WAP, exemplificando que a Internet não está restrita ao computador. 0 celular, embora seja um equipamento que também apresente diferentes configurações, tem a vantagem significativa de volume: em 2006, o Brasil atingiu a expressiva marca de 90 milhões de celulares. Adicionalmente, é um equipamento relativamente simples, de fácil aquisição e implantação, sobretudo quando comparado a um microcomputador.

Lições. Na visão do executivo responsável pela gestão dos canais de atendimento do Banco, a Internet, somada aos demais canais terminais de auto-atendimento, telefone e mobile banking, representa um potencial muito grande de captação de transações, por suas características de convergência, potencial este que a capacita a dotar um mesmo dispositivo com um conjunto cada vez maior de mídias e funcionalidades e de mobilidade.

Sobre a convergência, ele vai além: "O mundo físico fica cada vez menos relevante à medida que você tem uma capacidade plural de se comunicar e de se conectar. E, segundo essa visão, já não importa muito mais se é Internet, se é mobile, se é tel efone. $N$ ão conseguimos mais qualificar claramente o nome do dispositivo por força da convergência".

Para esse executivo, o atual momento tecnológico está provocando uma alteração profunda no processo de distribuição de serviços bancários, seja do ponto de vista transacional, agindo como alternativa para servir o cliente com custos reduzidos e com vantagens, seja ainda do ponto de vista comercial, reforçado por processos mais dinâmicos de relacionamento com os clientes. Esses processos baseiam-se em uma diferença muito sutil, mas importante: a capacidade de identificar o cliente antes de começar a desenvolver qual quer tipo de transação com ele.

As mudanças impulsionadas pelo momento tecnológico, para esse mesmo executivo do Banco, apresentam oportunidades e questões a serem respondidas: "Até que ponto o Banco está interpenetrando o business de telecomunicações, o business de tel efonia, o business de distribuição, o business de comércio eletrônico, quer dizer, como é que as relações 'B to $B$ ', 'B to $C^{\prime}$ e 'C to $C^{\prime}$ 'vão mudar nesse processo? Até que ponto o papel dos bancos vai ter uma rel evância maior ou menor? Acreditamos que nosso grande desafio é nos mantermos na cadeia de vaIor". Generalizando a partir dessa fala, parece que o futuro aponta mesmo para a convergência entre tecnologias, negócio e clientes. E assim, após uma década, a Internet, que de início era uma tecnologia quase marginal, foi se incorporando como infra-estrutura essencial aos processos de negócio do Banco.

\section{Eduardo H. Diniz}

Prof. do Departamento de Informática e Métodos Quantitativos Aplicados à Administração da FGV-EAESP Doutor em Administração pela FGV-EAESP E-mail:ediniz@fgvsp.br

\section{Heloísa Mônaco dos Santos}

Mestre em Administração de Empresas pela FGV-EAESP

E-mail: helomonaco@gvmail.br 